\title{
La magie, parfois triste, de New York
}

Jean Martin

\section{Jean Martin}

\begin{abstract}
Je ne vais en aucune manière bouder mon plaisir moi qui ne suis pas souvent passionné, là je le suis. Colum McCann est cet écrivain (encore jeune, né en 1965) d'origine irlandaise, vivant à New York. Il a publié plusieurs livres racontant des histoires hors du commun, extra-ordinaires. Quoique romans, ils sont basés sur des réalités historiques que l'auteur va rechercher dans des documents et aussi sur le terrain: en Slovaquie pour Zoli, histoire d'une femme rom durant la Seconde guerre mondiale, dans les bas-fonds de New York pour Les saisons de la nuit. Je recommande vivement Let the great world spin (traduction française: Et que le vaste monde poursuive sa course folle).
\end{abstract}

\section{«Talent de McCann de faire vivre l'existence quotidienne, ses vicissitudes et quelques joies.»}

L'histoire se tisse à New York et dans ses différents «boroughs» en 1974 (avec quelques dernières pages datées de 2006), autour d'un épisode acrobatique et esthétique devenu emblématique: la traversée en août 1974, sur un câble lancé entre les «Twin Towers» du World Trade Center, à 400 mètres de hauteur, du funambule français Philippe Petit. S'entremêlent les péripéties de vie de protagonistes bien différents: un jésuite qui, après une jeunesse difficile à Dublin, pratique la théologie de la libération en accueillant des prostituées noires dans le Bronx, et son frère arrivant d'Irlande en espérant réussir aux EtatsUnis; un groupe de cinq mères de milieux socio-économiques disparates, qui toutes ont perdu un fils à la guerre du Vietnam (qui dure encore) et se voient de temps en temps pour en parler. Un couple d'artistes des milieux artistiques branchés et très «swinging» autour de Greenwich Village. Une jeune veuve guatémaltèque qui voudrait devenir médecin et ses deux enfants. Des communications difficiles, des amours, des accidents et des morts dans ces existences. En arrière-fond, l'enfance des deux frères à Dublin, avec une mère musicienne très aimée, un père enseignant universitaire à Londres qui envoie un chèque mensuel mais qu'ils ne revoient qu'au décès de la mère. Dublin où on retrouvera brièvement le frère survivant (le jésuite meurt) trente ans plus tard. Et bien sûr la vie de la métropole urbaine qu'est New York. Un chapitre sur l'entraînement acrobatique très astreignant de Philippe Petit, durant des années.

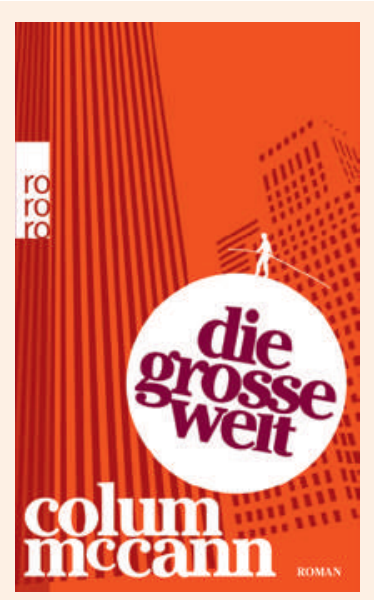

Colum McCann Die grosse Welt Berlin: Rowohlt; 2011 544 Seiten, $17.90 \mathrm{CHF}$ ISBN 978-3-499-24847-4

Talent de McCann de faire vivre l'existence quotidienne, ses vicissitudes et quelques joies. Tout en décrivant ces trajectoires humaines avec une sorte de recul, depuis l'extérieur en quelque sorte (même quand il se/nous met dans la peau d'une personne). Sans pathos; en nous laissant par exemple imaginer les sentiments d'une femme qui perd l'amour de sa vie, ceux d'une prostituée attachante dont la fille est tuée dans un accident de circulation et qui, parce qu'elle a commis quelques larcins et «pété les plombs» en prison, ne peut pas s'occuper de ses petites-filles, prunelles de ses yeux - elle doit les voir confiées par les services sociaux à une autre femme et se suicide en prison.

Description d'une époque, de ses drames (Vietnam), de ses excès (drogue, alcool, sexe - avant le sida!). On réalise que c'était avant Internet aussi, même si le fils d'une grande bourgeoise de Park Avenue tué à Saigon y était pour des tâches informatiques ultra-sophistiquées de type hacking. Juifs, catholiques, WASP (white anglo-saxon protestants), blancs, noirs, latinos; la prostitution de rue et les acrobaties dans le même registre dans la jet set. Le fonctionnement judiciaire et la différence entre le droit et la justice. Sans que McCann s'y appesantisse (en général, il ne s'appesantit précisément pas), la problématique du racisme et des discriminations est là aussi.

Plaisir de la lecture, propos direct, jamais alambiqué. Juste ce qu'il faut de formules argotiques américaines. On sent des parentés avec Hemingway, Philip Roth, John Irving. Substantiel. Profond. Gripping. Si ce livre vous tombe sous les yeux ou la main, prenez-le. 